\title{
Uso de energia elétrica e o desafio da sustentabilidade ambiental nas escolas da rede municipal de ensino de Fortaleza, Ceará, Brasil
}

\section{Maria Laudecy Ferreira de Carvalho ${ }^{1}$, Luan Gomes dos Santos de Oliveira ${ }^{2}$, Joel Silva dos Santos ${ }^{1}$, Ana Bárbara de Araújo Nunes $^{3}$ e Valdisia Vieira dos Santos Silva ${ }^{4}$}

\author{
${ }^{1}$ Universidade Federal da Paraíba. Programa de Pós-Graduação em \\ Desenvolvimento e Meio Ambiente. Campus I. João Pessoa-PB, Brasil (CEP 58051- \\ 900). E-mail: laudecyferreira@gmail.com. \\ ${ }^{2}$ Universidade Federal de Campina Grande. Centro de Ciências Jurídicas e Sociais. \\ Sousa-PB, Brasil (CEP 58800-240). \\ ${ }^{3}$ Universidade Federal do Ceará. Departamento de Engenharia Hidráulica e \\ Ambiental. Campus do Pici. Bloco 713. Fortaleza-CE, Brasil (CEP 60440-970). \\ ${ }^{4}$ Universidade Plus. Curso de Pós-Graduação em Gestão, Coordenação e Supervisão \\ Educacional. Campus Maraponga. Fortaleza-CE, Brasil (CEP 60710-684).
}

Resumo. Com a degradação ambiental ocasionada pelos diversos padrões de consumo e práticas insustentáveis, como o uso crescente de combustíveis fósseis para a produção de energia, a capacidade de carga e suporte do planeta vem sendo comprometida. Nesse sentido, o aumento da pegada ecológica e a crescente poluição e deterioração de diversos sistemas ambientais compromete cada vez mais o equilíbrio ecológico e a sustentabilidade planetária, ocasionando assim, uma série de problemas socioambientais. Diante deste contexto, é urgente a alfabetização ecológica dos futuros cidadãos para (re)pensar e (re)construir um modelo de sociedade que esteja pautada no tripé da sustentabilidade ambiental: social, econômico e ecológico. É nessa perspectiva, que o presente artigo tem como objetivo principal de verificar as ações de sustentabilidade ambiental, no que diz respeito, ao uso da energia elétrica em três escolas públicas municipais, junto aos alunos da $3^{\text {a }}$ a $9^{a}$ séries do Ensino Fundamental, localizadas no Município de Fortaleza, Ceará, Brasil: Escola Municipal Ari de Sá Cavalcante, Escola Municipal Professora Vânia Maria Neves Facó Barros (Unidade II) e Escola Municipal Papa João XXIII. Para a realização da pesquisa, inicialmente foi realizado um levantamento bibliográfico a respeito da temática em questão. A metodologia de base qualitativa utilizada pautou-se em pesquisa documental, pesquisa bibliográfica e aplicação de questionário semiestruturado e entrevista contendo 12 perguntas direcionadas ao público alvo das três escolas investigadas, no que diz respeito aos hábitos e costumes referentes ao consumo de energia elétrica, assim como o acompanhamento mensal da conta de luz e discussões diárias
Recebido

$16 / 09 / 2020$

Aceito

$00 / 10 / 2020$

Disponível on line

$00 / 10 / 2020$

Publicado

$31 / 12 / 2020$

Acesso aberto

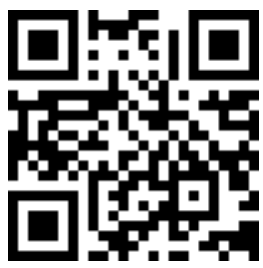

RCID

D) 0000-0002-4868-8997

Maria Laudecy

Ferreira de Carvalho

ISSN 2359-1412/RBGAS-2020-0137/2020/7/17/15/1241

Rev. Bras. Gest. Amb. Sustent.

http://revista.ecogestaobrasil.net 
nas salas de aula e na acolhida diária dos alunos no pátio da escola sobre o modelo de gestão e gerenciamento da energia elétrica utilizada pela escola. Os resultados sinalizaram que, os discentes na sua maioria deveriam reavaliar seus hábitos para com o uso da referida energia de modo a praticar a sustentabilidade socioambiental e econômica tanto na escola, quanto em casa e onde quer que esteja e que medidas de educação socioambiental como estas devem ser replicadas.

Palavras-chave: Sustentabilidade; Energia elétrica; Escola pública; Fortaleza; Ceará.

Abstract. Electricity use and the challenge of environmental
sustainability in municipal schools in the City of Fortaleza, Ceará, Brazil. With the environmental degradation caused by the various consumption patterns and unsustainable practices, such as the increasing use of fossil fuels for the production of energy, the load capacity and support of the planet has been compromised. In this sense, the increase in the ecological footprint and the increasing pollution and deterioration of various environmental systems increasingly compromises ecological balance and planetary sustainability, thus causing a series of socio-environmental problems. Given this context, the ecological literacy of future citizens is urgent in order to (re)think and (re)build a model of society that is guided by the tripod of environmental sustainability: social, economic and ecological. It is in this perspective, that the present article has as main objective to verify the actions of environmental sustainability, with regard to the use of electric energy in three municipal public schools, with students from the 3rd to the 9th grades of Elementary School, located in City of Fortaleza/Ceará: Municipal School Ari de Sá Cavalcante, Municipal School Professor Vânia Maria Neves Facó Barros (Unit II) and Municipal School Papa João XXIII. To carry out the research, a bibliographic survey was initially carried out on the subject in question. The qualitative base methodology used was based on documentary research, bibliographic research and application of a semi-structured questionnaire and interview containing 12 questions directed to the target audience of the three schools investigated, with regard to the habits and customs related to the consumption of electricity, as well such as the monthly monitoring of the electricity bill and daily discussions in the classrooms and in the daily reception of students in the school yard on the management model and management of electricity used by the school. The results signaled that the majority of students should reevaluate their habits with the use of said energy in order to practice socio-environmental and economic sustainability both at school, at home and wherever they are and that socio-environmental education measures such as these must be replicated.

Keywords: Sustainability; Electricity; Public school; Fortaleza; Ceará.
(ㄱ) $0000-0001-6642-0006$

Luan Gomes dos

Santos de Oliveira

(D) 0000-0002-8068-630X

Joel Silva dos Santos

D 0000-0001-6059-8540

Ana Bárbara de Araújo

Nunes

(1) 0000-0003-3770-5218

Valdísia Vieira dos

Santos Silva 


\section{Introdução}

Esta pesquisa surgiu da necessidade de rever o modelo e as práticas de uso de energia elétrica utilizado pelas escolas da rede municipal de ensino fundamental do Município de Fortaleza-Ceará. Observa-se, que o uso de energia fóssil ainda é bastante difundido e deve ser (re)pensado visando à implementação de fontes alternativas de energia que sejam menos degradantes e mais limpa. Sendo assim, tal problemática merece ser levada em discussão para a sala de aula e a comunidade escolar visando uma mudança e retomada de posição, no que diz respeito ao uso sustentável da energia elétrica nas escolas municipais investigadas: Escola Municipal Ari de Sá Cavalcante, Escola Municipal Professora Vânia Maria Neves Facó Barros (Unidade II) e Escola Municipal Papa João XXIII, com os alunos da 3a a 9a séries do Ensino Fundamental. As escolas públicas do Município de Fortaleza na sua maioria devem adotar práticas educativas que versem sobre a importância da educação ambiental, no que se refere à mitigação e/ou substituição do uso de combustível fóssil. Nesse contexto, a alfabetização ecológica torna-se um dos caminhos viáveis na formação de cidadãos conscientes e responsáveis. A educação ambiental é um dos caminhos a ser trilhado na busca pela sustentabilidade socioambiental.

O Brasil, através da Lei no 9.795/1999 (Brasil, 1999), que trata da Política Nacional de Educação Ambiental (PNEA), diz nos seus 21 artigos como deve funcionar a referida política e define no seu art. $1^{\circ}$ a educação ambiental como sendo:

[...] os processos por meio dos quais o indivíduo e a coletividade constroem valores sociais, conhecimentos, habilidades, atitudes e competências voltadas para a conservação do meio ambiente, bem de uso comum do povo, essencial à sadia qualidade de vida e sua sustentabilidade (Brasil, 1999).

Para compreender a educação ambiental na Lei da Política Nacional de Educação Ambiental (PNEA), o seu art. 2ำ diz: "a educação ambiental é um componente essencial e permanente da educação nacional, devendo estar presente, de forma articulada, em todos os níveis e modalidades do processo educativo, em caráter formal e não-formal" (Brasil, 1999). Neste sentido,

[...] vale destacar que a educação ambiental não pode ser desvinculada do drama que vivem a humanidade e o planeta. Cabe a ela fornecer instrumentos para que as pessoas e as organizações que assumem responsabilidades possam responder aos principais desafios do mundo de hoje. Caminhando por esse raciocínio, chegamos à hipótese de que, mais do que de educação ambiental, devamos falar de "educação para a sustentabilidade" (Leroy e Pacheco, 2006, p. 36).

Ainda, que a Política Nacional de Educação Ambiental, no seu art. 10, possa afirmar que "a educação ambiental será desenvolvida como uma prática educativa integrada, contínua e permanente em todos os níveis e modalidades do ensino formal" (Brasil, 1999), a educação para a sustentabilidade também pode ser praticada de maneira informal.

Ao tratar sobre quem tem direito à educação ambiental, o art. 3ํ da PNEA diz que "como parte do processo educativo mais amplo, todos têm direito igual à educação ambiental, incumbindo":

I - ao Poder Público, nos termos dos arts. 205 e 225 da Constituição Federal, definir políticas públicas que incorporem a dimensão ambiental, promover a educação ambiental em todos os níveis de ensino e o engajamento da sociedade na conservação, recuperação e melhoria do meio ambiente; 
II - às instituições educativas, promover a educação ambiental de maneira integrada aos programas educacionais que desenvolvem;

III - aos órgãos integrantes do Sistema Nacional de Meio Ambiente - Sisnama, promover ações de educação ambiental integradas aos programas de conservação, recuperação e melhoria do meio ambiente;

IV - aos meios de comunicação de massa, colaborar de maneira ativa e permanente na disseminação de informações e práticas educativas sobre meio ambiente e incorporar a dimensão ambiental em sua programação;

$\mathrm{V}$ - às empresas, entidades de classe, instituições públicas e privadas, promover programas destinados à capacitação dos trabalhadores, visando à melhoria e ao controle efetivo sobre o ambiente de trabalho, bem como sobre as repercussões do processo produtivo no meio ambiente;

VI - à sociedade como um todo, manter atenção permanente à formação de valores, atitudes e habilidades que propiciem a atuação individual e coletiva voltada para a prevenção, a identificação e a solução de problemas ambientais (Brasil, 1999).

A promoção do uso sustentável dos recursos naturais, nesse caso, combustíveis fósseis, perpassa pela educação para a sustentabilidade a ser praticada em ambientes escolares e não formal. Diversos acordos internacionais foram firmados visando a estabelecer o uso consciente e sustentável dos recursos naturais. Neste sentido, Martins (2018), afirma que o Brasil assumiu o compromisso de deixar de usar prioritariamente fontes de energia fóssil como o petróleo, com base no Protocolo de Kyoto (1997). É com base nesse compromisso que deve mitigar ou substituir por meio de fontes renováveis o uso da energia elétrica nas escolas. Afinal, sabe-se que esta fonte de energia não é renovável e que degrada o meio ambiente. Um dos principais efeitos é a emissão de gases poluentes que contribuem para o efeito estufa antropogênico.

Segundo Diegues (1996), a natureza é um sistema vivo com processos e funções próprias, ou seja, não pode ser comprometida como uma fonte inesgotável de matériaprima. Desta forma, é preciso regulamentar a relação entre sociedade-natureza de forma que os princípios do desenvolvimento sustentável cheguem com veemência às dimensões sociais, éticas, econômicas, tecnológicas e culturais da sociedade em geral. Sabe-se que uma sociedade sustentável é aquela capaz de reorganizar os espaços, eliminar as deseconomias de aglomeração, gerir novas economias externas, melhorar a qualidade de vida das populações e superar as desigualdades socioeconômicas para o crescimento econômico (Alva, 1997).

Neste sentido, vale destacar que a qualidade de vida está associada à melhoria dos indicadores que compõem o bem-estar social, saúde pública, a vida comunitária, a vida social e recreativa, bem-estar ambiental e qualidade estética. Para isso, faz-se necessário a importância do acompanhamento das mudanças por meio de sistemas de indicadores socioambientais que possam direcionar o caminho a ser trilhado. A sustentabilidade diz respeito à busca do bem-estar da população a longo prazo o que significa dar suporte às necessidades material e não materiais dos seus habitantes incluindo a questão ambiental e à aprendizagem coletiva para lidar com as diferenças e os conflitos das vontades. Tudo isso implica na participação de todos os agentes desse processo e desemboca no conceito de justiça social (Buss, 2012; Alves, 2016).

Neste contexto, de forma a ampliar essa argumentação, vale ressaltar que:

A sustentabilidade é também articulada por um discurso da ética, que elabora a conduta humana diante dos valores construídos de bem e de mal. Destacam-se aqui as intenções das ações que têm por objeto uma base material biofisicamente comum, interligando espaços, homens e tempos. É perceptível, igualmente, que tais ações e os juízos que se aplicam sobre elas ocorrem em condições de acentuada desigualdade jurídica, econômica e política de acesso ao espaço ambiental pelos distintos agentes sociais. Abandonadas as preocupações econômicas com os meios, 
surgem então questões relativas aos fins socialmente desejáveis. E a possibilidade de fins alternativos limita a desejabilidade da produção material crescente como fim último. Ainda que frequentemente subordinada aos discursos da equidade e da limitação responsável das escalas de crescimento, a proposta ética associa, assim, à sustentabilidade um discurso atualizado sobre deveres e obrigações morais relativos às condições de existência da vida (Acserald, 2009, p. 52).

Sabendo que o meio ambiente é a soma total do que está em torno de algo ou alguém, como por exemplo, os seres vivos e as forças naturais, faz-se necessário a prática de educação ambiental para que assim possa haver interação e colaboração entre os diferentes atores sociais em prol da sustentabilidade (Sauvé, 2000).

Percebe-se assim, que é preciso compreender as questões ambientais para além de suas dimensões biológicas, químicas, físicas, ou seja, o debate ambiental diz respeito às questões sociopolíticas. Desta forma, o que estrutura dialeticamente a questão socioambiental contemporânea é que:

[...] a análise da crise ambiental contemporânea deve partir das próprias contradições no interior da sociedade humana, contradições que não são biológicas, mas sociais, que não se baseiam na evolução genética, mas na história econômica, que não têm raízes nas contradições ecológicas em geral, mas naquelas que se estabelecem entre classes e setores sociais em particular (Foladori, 2001, p. 45).

Diante desse contexto, vale ressaltar que a problemática aqui evidenciada é o modelo de gestão e gerenciamento de energia elétrica utilizada por diversos atores sociais em três escolas públicas da rede municipal de ensino do Município de Fortaleza. Sendo assim, partiu-se do pressuposto de que é preciso atentar para a dimensão ambiental do uso da energia elétrica nessas escolas, tendo em vista que a educação ambiental é o caminho para a promoção da tomada de consciência ambiental e compreensão da evolução do meio físico, biológico e antrópico. Faz-se necessário, que o uso dos recursos naturais e a conservação racional destes recursos promovam o almejado desenvolvimento sustentável (Schmieder, 1977).

Ao perceber que as lâmpadas e ventiladores ficavam ligados sem que tivesse necessidade de uso nas salas de aula e pátios das escolas públicas municipais investigadas - Escola Municipal Ari de Sá Cavalcante - Escola Municipal Professora Vânia Maria Neves Facó Barros (Unidade - II) e Escola Municipal Papa João XXIII, foram apresentadas estratégias de ação de intervenção à gestão escolar das referidas unidades escolares a fim de implementar um projeto sobre a contenção de energia elétrica nas três escolas que poderia impactar no processo de na educação ambiental da comunidade escolar e na conta de energia elétrica dessas unidades de ensino fundamental. A gestão escolar por sua vez abraçou a causa por entender que o projeto de educação ambiental em discussão traria diversos ganhos de recursos financeiros para entidade mantenedora (Prefeitura Municipal de Fortaleza-Ceará). Assim como, diminuir a conta de energia elétrica, também havia a preocupação com a crescente degradação ambiental ocasionada pelo uso desse combustível fóssil (a exemplo do petróleo que é uma energia não renovável) gerando enormes desequilíbrios e/ ou conflitos ambientais e econômicos. Frente a essa realidade, pesquisadores de todo o mundo têm proposto soluções no sentido da sustentabilidade socioambiental apontando como uma das alternativas o uso de energias renováveis (Cervi e Carvalho, 2016).

Após discussão entre a comunidade escolar, em 2019, criou-se o projeto de educação ambiental titulado "Essa luz não pode parar! nossa escola vem economizar!". 0 referido projeto de educação ambiental teve como objetivo analisar as ações da comunidade escolar que consistia em uma via da educação popular, capaz de gerar 
mudanças de hábito e práticas sociais e políticas do uso da energia elétrica no dia a dia de todos que faziam parte das escolas públicas municipais Escola Municipal Ari de Sá Cavalcante, Escola Municipal Professora Vânia Maria Neves Facó Barros (Unidade II) e Escola Municipal Papa João XXIII da rede municipal de ensino de Fortaleza. Esse projeto foi tomado como referência para a base deste estudo.

\section{Metodologia}

A metodologia, de natureza qualitativa, utilizada nesta pesquisa foi composta por coleta de dados de campo, pesquisa documental, pesquisa bibliográfica e aplicação de questionários e realização de entrevistas junto à comunidade escolar das escolas públicas municipais de Fortaleza, no Estado do Ceará. 0 trabalho trata-se de uma pesquisa ação, pois além de investigar a problemática, propõe soluções de maneira simultânea.

Para a pesquisa in loco foram selecionadas três escolas da rede pública municipal de ensino do Município de Fortaleza: Escola Municipal Ari de Sá Cavalcante, a Escola Municipal Professora Vânia Maria Neves Facó Barros (Unidade II) e a Escola Municipal Papa João XXIII. E o critério de escolha das escolas veio por meio do engajamento com a temática em discussão, da prática pedagógica de uma das autoras deste artigo, Maria Laudecy Ferreira de Carvalho, nas referidas escolas onde a mesma atuou na função de professora.

\section{Caracterização das áreas de estudo}

Escola Municipal Ari de Sá Cavalcante: Foi fundada em 23 de outubro de 1972, atende um total de 590 alunos da $3^{\text {a }}$ a $9^{\text {a }}$ séries do Ensino Fundamental e um total de 32 professores, 6 funcionários, 1 supervisora e 4 gestores. A escola possui internet e funciona nos turnos manhã e tarde, no Bairro José Walter, no Município de Fortaleza. A referida escola contou com um total de 633 participantes do estudo em discussão.

Escola Municipal Professora Vânia Maria Neves Facó Barros (Unidade II): A escola Vânia Neves (Unidade II) tem um total de 219 alunos da $3^{\text {a }}$ a $5^{\text {a }}$ séries do Ensino Fundamental e possui um total de 12 professores, 7 funcionários, 1 secretário 1 Coordenadora Pedagógica. A escola possui internet e funciona nos turnos manhã e tarde e foi fundada em 03 de janeiro de 2000. Portanto, a referida escola na sua totalidade participou da implantação da pesquisa, ou seja, mais de 240 pessoas aderiram à aplicação do projeto de educação ambiental em busca da contenção de energia elétrica.

Escola Municipal Papa João XXIII: A escola Papa João XXIII atende um total de 684 alunos da $3^{\text {a }}$ a $5^{\text {a }}$ séries do Ensino Fundamental com um total de 32 professores, 9 funcionários, 1 secretário 2 coordenadoras pedagógicas e 1 Diretor Geral e 4 Agentes Administrativos. Assim sendo, a referida escola contou com um total de 733 participantes do estudo em discussão. A escola tem internet e funciona nos turnos manhã e tarde e foi fundada em 10 de agosto de 1964.

\section{Os atores sociais das escolas públicas municipais}

A aplicação do questionário temático e a realização de entrevista a respeito da temática uso de energia elétrica nas escolas investigadas se deu com Zeladores, Professores, representantes de sala, alunos das escolas, Secretários, Coordenação Pedagógica e Gestores das três escolas. 0 objetivo era detectar se a mudança de hábito nas ações do dia a dia da comunidade escolar causaria impacto positivo nas contas de energia elétrica e no setor da economia da escola com redução também dos impactos ambientais. A partir dos resultados dos questionários e entrevistas foi possível documentar e confrontar opiniões sobre as ações do antes e do depois da aplicação do projeto. A escolha 
dos entrevistados para a aplicação do questionário e da entrevista foi realizada de forma espontânea por meio de consultas no ambiente escolar.

Por se tratar de uma pesquisa-ação, o trabalho também se propôs a estabelecer práticas educativas no dia a dia dos estudantes durante um período de 60 dias, especialmente no que diz respeito ao uso de energia elétrica na escola. Sendo assim, o trabalho também se propôs:

1) desligar ar condicionado, ventiladores e lâmpadas nos ambientes da escola quando não estiverem em uso;

2) mobilizar todos que fazem parte da escola para esta tomada de consciência;

3) convidar a zeladora a ser parceira fundamental nessa vigilância da contenção da energia, mantendo ventiladores, lâmpadas e ar condicionado desligados quando não estiver em uso;

4) convocar representantes ou líderes de sala de aula para serem parceiros importantes nessa tomada de consciência: fiscalizar se os referidos equipamentos estão desligados quando não estiver em uso.

5) acompanhar o consumo da conta de energia no decorrer da execução e comparar com o antes e o depois do projeto.

\section{Resultados e discussão}

Mais de 1.606 pessoas executaram as ações de redução de consumo de energia elétrica durante a pesquisa nas três escolas municipais de Fortaleza, no ano de 2019, para o uso eficiente de energia elétrica no desenvolvimento de suas atividades diárias junto à comunidade escolar.

Diante do pesquisado e em resposta à entrevista e questionário aplicado nas escolas supracitadas, viu-se que em nenhuma das três escolas em estudo realizavam ações de sustentabilidade para com o uso da energia elétrica (fóssil). Quando foi perguntado sobre se havia ou não o desligamento diário de ventiladores e lâmpadas sem que estas estivessem em uso nos seus espaços na escola, a resposta foi de que ninguém tinha atentado a essa prática. Ou seja, mais de 21 anos da existência da Lei da Política Nacional de Educação Ambiental e as práticas de educação ambiental ainda são insuficientes nos espaços escolares em estudo.

Ainda, ao ser indagado sobre se alguém tinha ideia de quanto seria o custo mensal da conta de energia elétrica, todos disseram que não tinham ideia do valor de consumo de energia elétrica da escola. Ao perguntar sobre qual disciplina ou componente curricular tinha trabalhado a educação ambiental com relação ao uso dos combustíveis fósseis na escola, todos responderam que nunca tinham discutido esse modelo de prática na escola, eis porque não tinham o cuidado em desligar lâmpadas nem ventiladores nos espaços da escola. Assim sendo, observou-se que é insuficiente a aplicabilidade da lei de educação ambiental junto aos ambientes escolares em análise no que se refere a "educação ambiental ser desenvolvida como uma prática educativa integrada, contínua e permanente em todos os níveis e modalidades do ensino formal" de acordo com o art. 10 da Política Nacional de Educação Ambiental (Brasil, 1999).

Ao responderem sobre o que mudou em suas vidas depois da execução do projeto de educação ambiental na escola, estes responderam que o cuidado com o meio ambiente fez toda diferença em suas vidas. A conta de energia da sua casa veio com um percentual reduzido de consumo em torno de $45 \%$ mês. 0 que ajudaria muito nas despesas com alimentação e vestuário, dentre outros. Ainda ajudaria ao meio ambiente, pois mitigaria o seu uso e evitaria a degradação ambiental na ocupação de grandes espaços para se implantar uma usina hidrelétrica. Também que havia percebido que por meio das práticas de uso de maneira sustentável o valor do consumo de energia elétrica na escola tinha reduzido de forma significativa como nos exemplos das tabelas e figuras a seguir. 
As figuras a seguir remetem discussões para a tomada de consciência de práticas sustentáveis nos ambientes escolares.

A Figura 1 mostra as salas de aula da escola "A" com suas lâmpadas ligadas sem que tivessem em uso pela comunidade escolar.
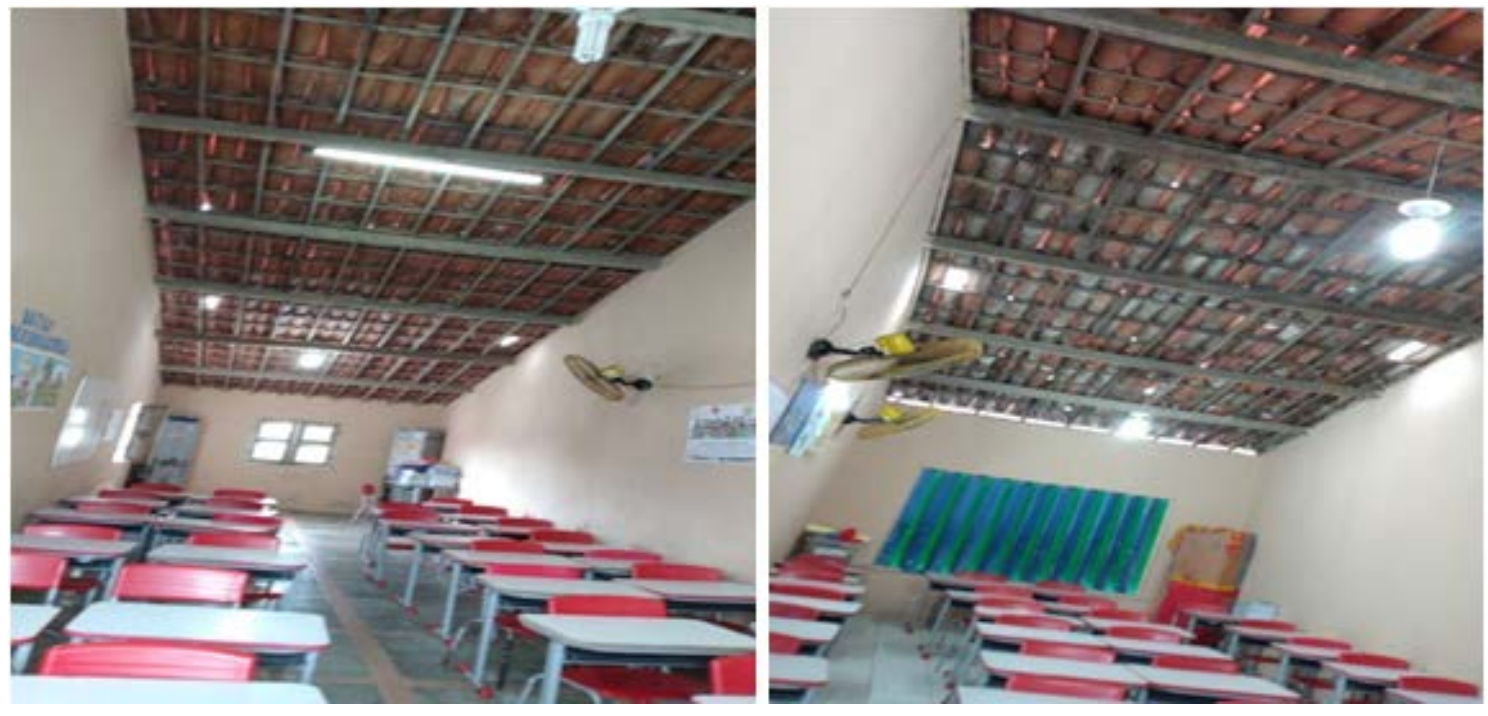

Figura 1. Lâmpadas das salas de aula da escola " $A$ ".

Diante das imagens das salas de aula da escola " $\mathrm{A}$ ", foi possível perceber que durante os horários que antecederam e sucederam as aulas, assim como os intervalos, ou seja, horário em que não tem atendimento ao aluno(a), todas as lâmpadas e ventiladores desses espaços escolares estão ligadas, podendo ocasionar desperdício de energia elétrica, matéria prima, dinheiro, insuficiência de sustentabilidade ambiental,dentre outros. Ainda, desta forma aumentar o consumo de energia elétrica resultando em insustentabilidade econômica e ambiental, cultural e educacional. Para confirmar essa insuficiência socioambiental e econômica observe a Tabela 1 a seguir:

Tabela 1. Amostra do consumo de energia elétrica da Escola "A" em 2019.

\begin{tabular}{|l|c|}
\hline Mês & Consumo (kWh) \\
\hline Agosto & 635 \\
\hline Setembro & 613 \\
\hline Outubro & 1.907 \\
\hline
\end{tabular}

Fonte: Sistema de Gestão da Escola, Secretaria Municipal da Educação de Fortaleza, Ceará, 2019.

O acompanhamento e economia da conta de energia da escola " $A$ " foi significante, chegando em torno da média de $67,85 \%$ de economia no consumo, como podemos perceber na Tabela 1.

De acordo com a Tabela 1 observou- se que nos meses de agosto e setembro onde foi realizado o projeto de contenção de energia, a quantidade do consumo mês comparada 
ao mês de agosto foi reduzida para $1.272 \mathrm{kWh}$ ou $66,70 \%$ e comparada ao mês de outubro foi de $1.294 \mathrm{kWh}$ ou $67,85 \%$. Portanto, a economia representa um resultado relevante economicamente e socioambientalmente.

A Figura 2 a seguir apresenta os alunos da $4^{\underline{a}}$ série do Ensino Fundamental da escola "A" na apresentação da peça teatral sobre educação ambiental em prol da contenção de energia elétrica.

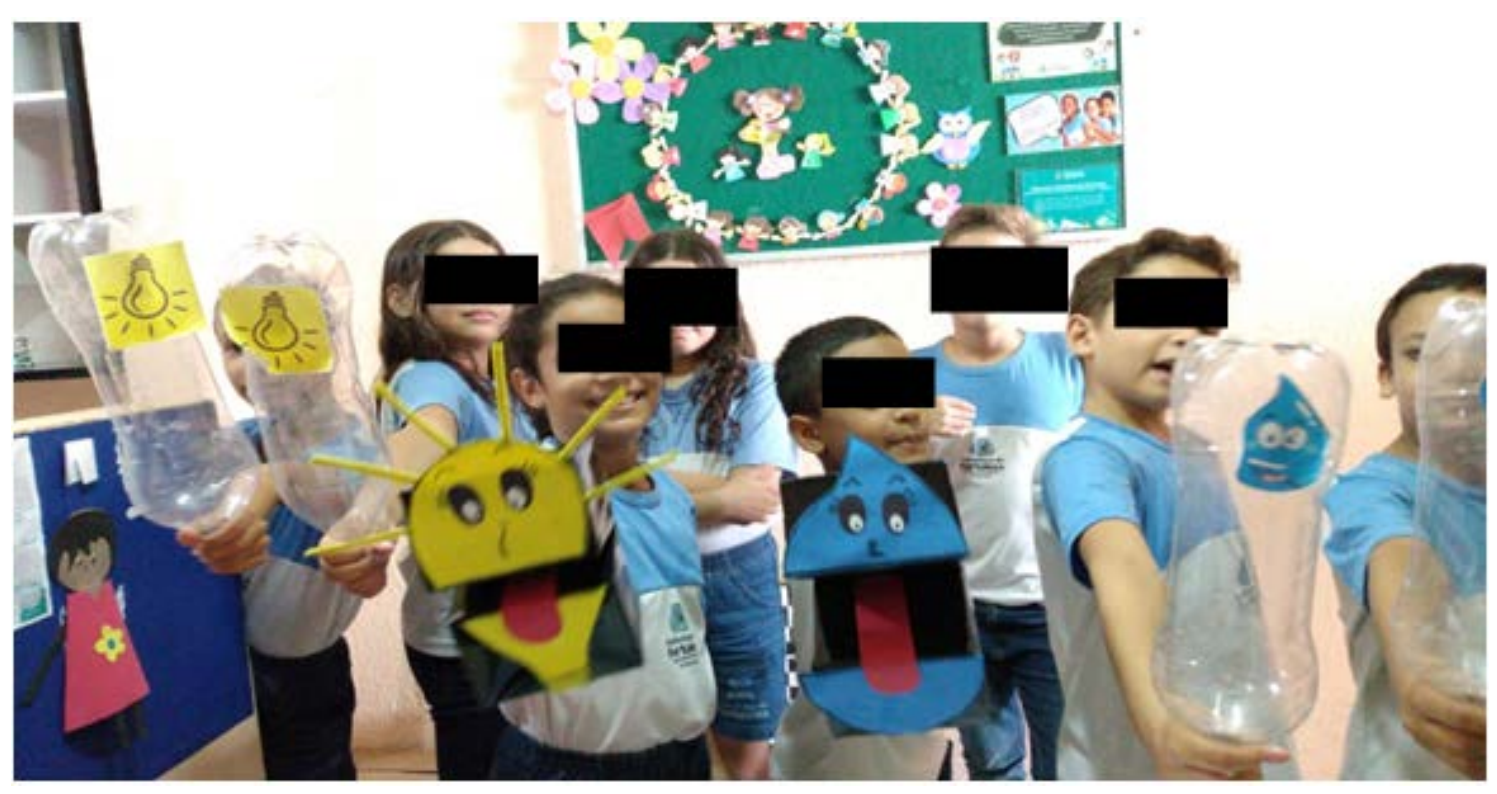

Figura 2. Apresentação da peça teatral: Essa escola é sustentável! Juntos pela contenção de água e energia elétrica - Escola "A". 2019.

Na Figura 2 é possível perceber o engajamento social dos estudantes ao apresentar a peça teatral sobre educação ambiental no ambiente escolar.

A Figura 3 a seguir mostra as lâmpadas ligadas sem que o espaço estivesse em uso, ou seja, gerando desperdício ambiental e econômico.

Figura 3. Iluminação do ambiente interno da escola "B". 2019.

Rev. Bras. Gest. Amb. Sustent., 2020, vol. 7, n. 17, p. 1241-1256. 
Percebeu-se que durante o dia mesmo existindo a luz solar para iluminar o ambiente escolar, todas as lâmpadas dos ambientes da escola "B" estavam ligadas e causando desperdício de energia elétrica impactando negativamente no meio ambiente e, desta forma aumentando o consumo de energia elétrica do referido espaço escolar que resulta em gastar mais dinheiro com o pagamento da conta de energia. Portanto, diante da situação e com base nas imagens, a luz solar seria o suficiente para iluminar o local em discussão.

Para fazer a análise dessa situação foi consultada a conta de energia elétrica da escola "B" durante os meses de realização do projeto como apresenta a tabela a seguir.

Outra situação relevante nas ações da referida escola foi com relação ao acesso junto às contas de consumo de energia e poder comparar os valores de consumo dos meses anteriores e posteriores à prática do projeto por toda comunidade escolar. A Tabela 2 a seguir a presenta os valores desses consumos.

Tabela 2. Amostra do consumo de energia elétrica da Escola “B”, 2019.

\begin{tabular}{|l|c|}
\hline Mês & Consumo (kWh) \\
\hline Setembro & 4.228 \\
\hline Outubro & 4.058 \\
\hline Novembro & 4.556 \\
\hline
\end{tabular}

Fonte: Sistema de Gestão da Escola, Secretaria Municipal da Educação de Fortaleza, Ceará, 2019.

O acompanhamento e economia da conta de energia da escola "B" foi significante, como pode perceber na Tabela 2, embora, vale ressaltar que houve um imprevisto, no décimo dia da aplicação do projeto de contenção da energia elétrica foram instalados 5 centrais de ar condicionado, ou seja, mesmo com a instalação das mesmas ainda foi possível haver a redução da conta de energia em relação ao mês de novembro onde já não estava acontecendo o projeto.

De acordo com a tabela observou- se que nos meses de setembro e outubro onde foi realizado o projeto de contenção de energia, a quantidade de consumo mês de setembro se comparada ao mês de novembro houve uma redução de 328 kWh ou 7,19\% e o mês de outubro se comparada ao mês de novembro foi de 498 kWh ou 10,93\%. Portanto, a economia representa um resultado relevante economicamente e ambientalmente mesmo com a instalação dos novos equipamentos elétricos no local.

Ações como afixar nas paredes das salas de aula, nos corredores e pátio da escola cartazes com a indicação da importância de fazer a contenção de energia e, diariamente os professores dialogarem a respeito destes, foram passos importantes para a mudança de hábitos da comunidade escolar. A seguir na Figura 4 o modelo do cartaz.

0 texto do cartaz da Figura 4, diariamente era discutido pelos alunos nos ambientes da escola, assim como a sua relação com o comportamento na família.

Durante a execução do projeto, foi sugerido realizar peça teatral como forma de motivar, despertar e incentivar os participantes a economizar energia elétrica e água.

Outra ação muito importante aconteceu com a apresentação de peça teatral encenada pelos alunos da 4⿳亠丷厂 Série do Ensino Fundamental, onde foi apresentado os custos na economia de energia elétrica depois da prática do projeto. A economia chegou a mais de trezentos reais mês. Um valor considerado relevante na economia dos recursos ambientais e econômicos. A seguir fotos da peça teatral da Escola "B". 
Figura 4. Modelo de cartaz afixado nas salas de aula e pátio da escola. 2019.

A Figura 5 a seguir mostra o ensaio da peça teatral com os alunos da 4⿳⺈. Série do Ensino Fundamental.

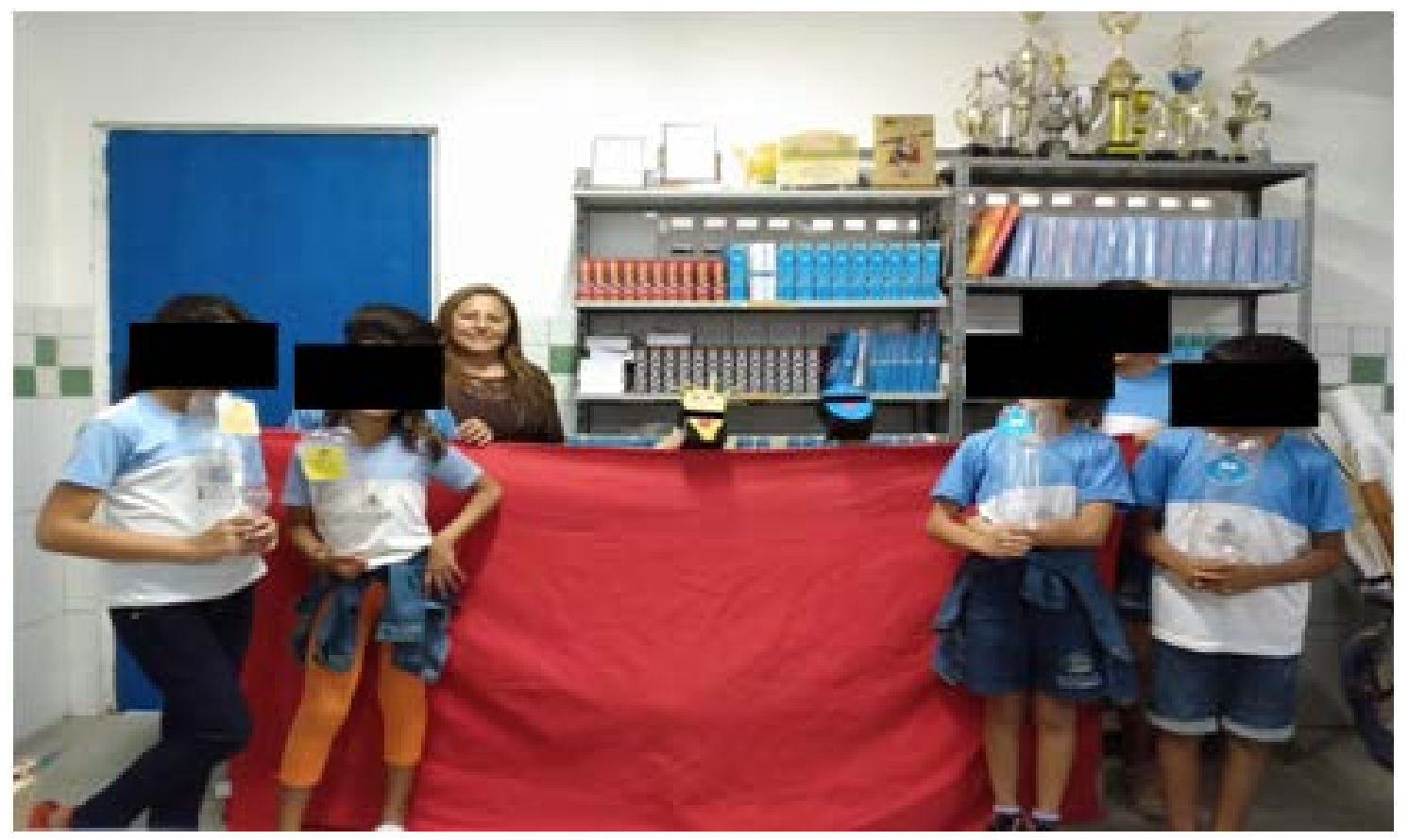

Figura 5. Ensaio da peça teatral na biblioteca da escola. 2019.

O momento do ensaio foi de muita expectativa entre os atores da peça teatral. Foi possível observar o quanto aquela temática estava sendo bem relacionada entre todos da escola.

Rev. Bras. Gest. Amb. Sustent., 2020, vol. 7, n. 17, p. 1241-1256. 
Ao chegar o momento da apresentação da peça teatral era notável a atenção de todos. 0 que demonstrou ser de interesse a temática de educação ambiental e que quando o projeto foi feito por meio da conscientização de forma a interagir com seu dia a dia, a motivação acontecia de forma plena. A Figura 6 a seguir mostra a comunidade escolar da escola " $B$ " em um dos momentos de conscientização do uso adequado da energia elétrica na escola.

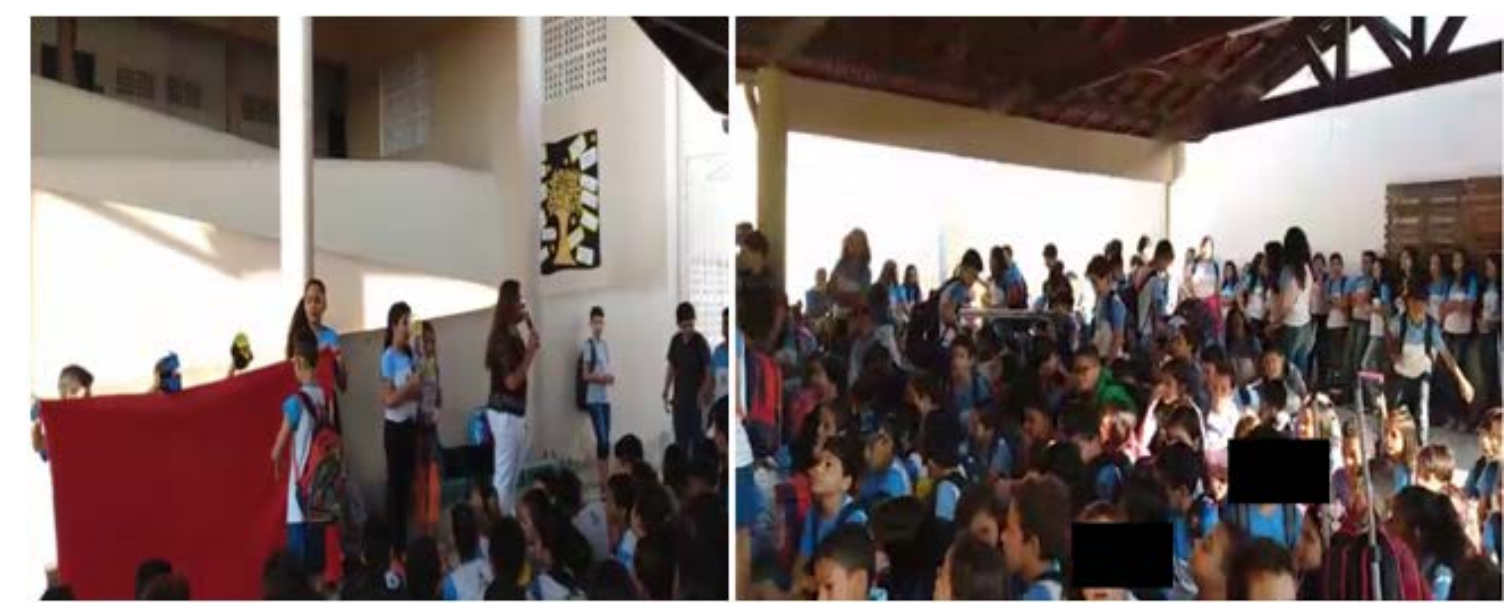

Figura 6. Apresentação da peça teatral: Essa escola é sustentável! Juntos pela contenção de água e energia elétrica - Escola "B". 2019.

A partir do diálogo de forma contínua no pátio e nas salas de aula da escola "B" pode se perceber quão eficiente foi aquela ação em prol da sensibilização por prática de educação ambiental no ambiente escolar. E que esse tipo de ação passou a ser replicado nas residências da referida comunidade escolar.

A Figura 7 apresenta a culminância do projeto no combate ao desperdício de energia elétrica na escola. Como foi visto, existe um fantoche no formato de uma gota de água representando o combate ao desperdício de água e outro fantoche no formato de lâmpada representando o combate ao desperdício da energia elétrica na escola.

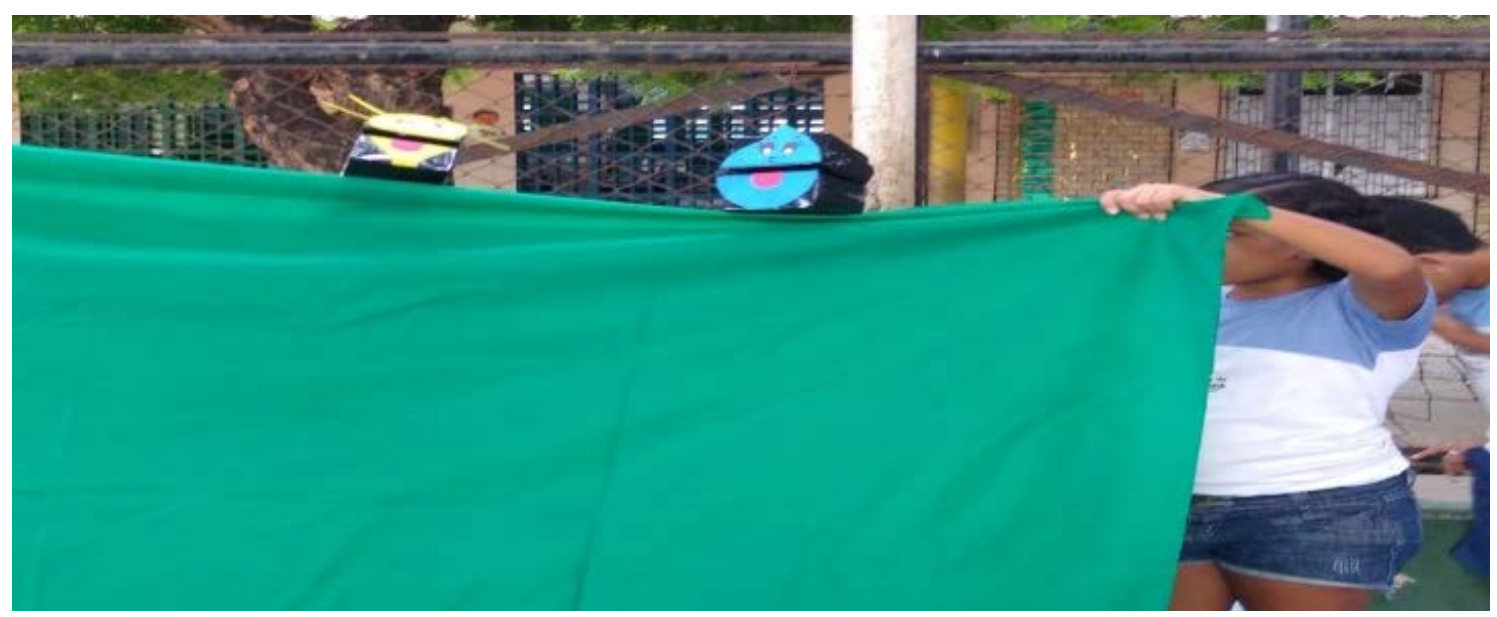

Figura 7. Apresentação da peça teatral: Essa escola é sustentável! Juntos pela contenção de água e energia elétrica - Escola "C". 2019. 
A Figura 8, mostra no pátio da escola "A", os alunos sendo protagonistas da ação contra o desperdício de energia elétrica. Ao serem consultados sobre o que significava aquele momento em suas vidas, eles responderam que se sentiam felizes por ter aprendido cuidar do meio ambiente de forma adequada. A economia de energia e água como sendo uma forma de melhorar a qualidade de vida do meio ambiente e que a ideia estava sendo aplicada em suas moradias.
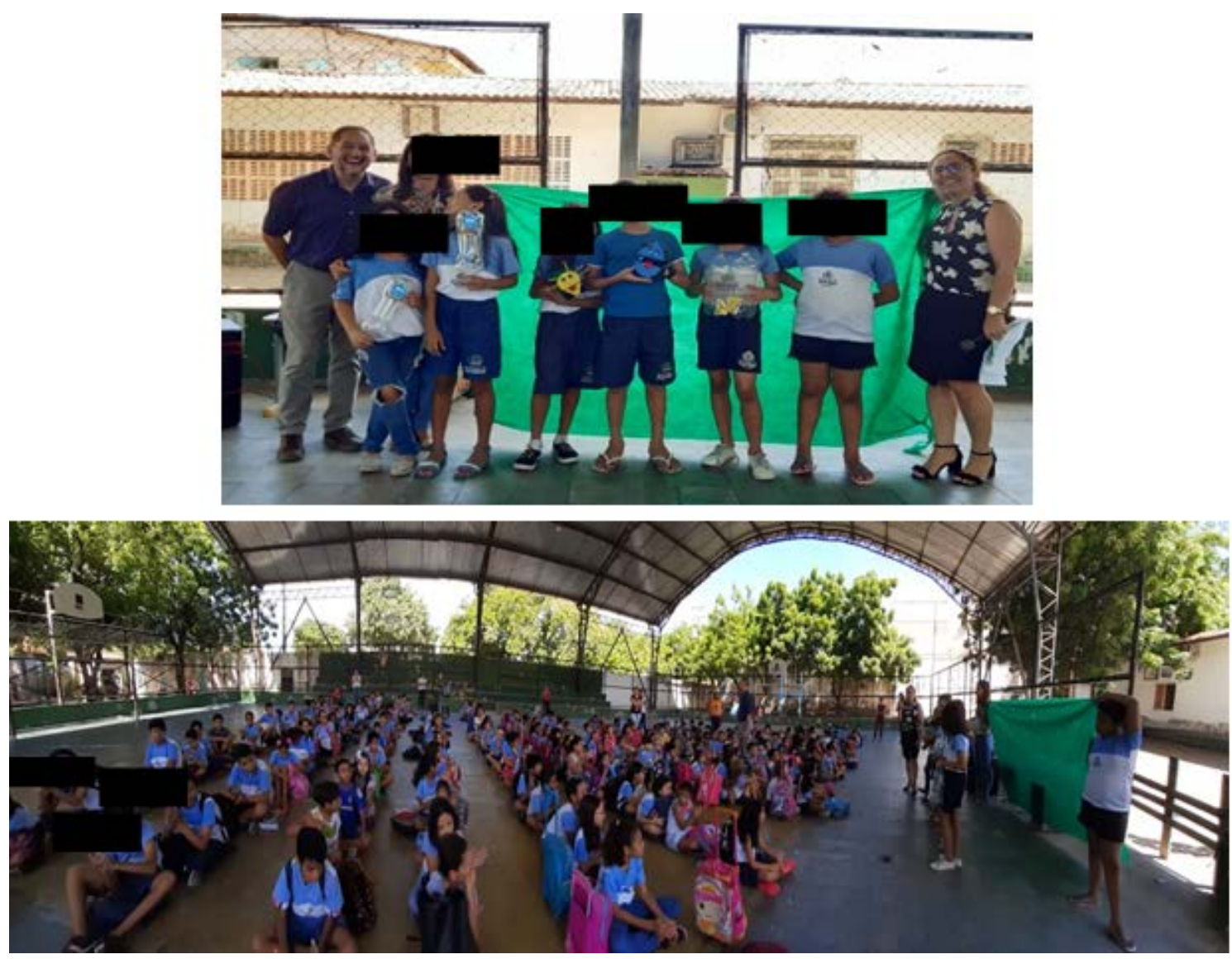

Figura 8. Pátio da escola "A", com os alunos sendo protagonistas da ação contra o desperdício de energia elétrica. 2019.

O acompanhamento e economia da conta de energia da escola "C" foi relevante, como pode ser percebido na Tabela 3.

Tabela 3. Amostra do consumo de energia elétrica da Escola "C".

\begin{tabular}{|l|c|}
\hline Mês & Consumo (kW h) \\
\hline Setembro & 1.297 \\
\hline Outubro & 1.248 \\
\hline Novembro & 3.989 \\
\hline
\end{tabular}

Fonte: Sistema de Gestão da Escola, Secretaria Municipal da Educação de Fortaleza, Ceará, 2019. 
A escola "C" apresentou resultados relevantes no combate ao desperdício de energia elétrica durante a execução do projeto. Isto significa que a ideia de economizar energia elétrica é eficiente e deve ser replicada por outras escolas. Com base na Tabela 3 observou-se que nos meses de setembro e outubro onde foi realizado o projeto de contenção de energia, a quantidade de consumo do mês de setembro comparada ao mês de novembro foi reduzida em $2.692 \mathrm{kWh}$ ou $67,48 \%$ e comparada ao mês de outubro foi de $2.741 \mathrm{kWh}$ ou $68,71 \%$. Portanto, a economia representa um resultado relevante economicamente e ambientalmente.

A partir do que disse Morin (1977, p. 122) "o todo só funciona como o todo, se as partes funcionarem como partes", e, "o todo está na parte assim como a parte está no todo", ou seja, a educação ambiental deve ser compartilhada por todos que integram o meio ambiente, a comunidade escolar em estudo e a sociedade.

Apesar da Lei da Política Nacional de Educação Ambiental afirmar, no seu art. 11, que "a dimensão ambiental deve constar dos currículos de formação de professores, em todos os níveis e em todas as disciplinas", e no seu parágrafo único assegurar que, "os professores em atividade devem receber formação complementar em suas áreas de atuação, com o propósito de atender adequadamente ao cumprimento dos princípios e objetivos da Política Nacional de Educação Ambiental", não foi isso que se observou na realidade vivenciada pelas referidas escolas, mesmo com a afirmação de que trata ainda o seu artigo 12 sobre a autorização e supervisão do funcionamento, onde as "instituições de ensino e de seus cursos, nas redes pública e privada, observarão o cumprimento do disposto nos arts. 10 e 11" da referida lei (Brasil, 1999). Portanto, como se viu o Brasil na sua PNEA atribui, determina e assegura a efetivação da política de educação ambiental, embora a sua prática seja insuficiente.

Apesar da Lei da Política Nacional de Educação Ambiental (Brasil, 1999) afirmar nos artigos supracitados que a educação ambiental deve ser um elemento essencial e permanente como prática integrada em todos os níveis e modalidades de ensino, em todas as disciplinas ou componentes curriculares e que deve existir uma supervisão para que se efetive a educação ambiental, isso não é o que se viu no dia a dia das escolas em estudo, assim como no que se refere ao desperdício da energia elétrica. Desta forma, é relevante ressaltar que:

A responsabilidade pelos principais problemas ambientais decorrentes do uso das diversas formas de energia depende fortemente da condição socioeconômica da sociedade. Em um mesmo país, as diferentes classes sociais consomem formas e quantidades diferentes de energia (Vianna, 2001, p. 167).

Portanto, fazendo-se necessário a aplicabilidade da lei no campo de estudo em discussão. Assim como, a necessidade de mobilizar currículos sociais e práticas educativas em torno da educação ambiental crítica.

\section{Conclusão}

A partir dos dados apresentados nesta pesquisa, pode -se perceber a grande importância de praticar a educação ambiental de forma efetiva e contínua de modo a promover a sustentabilidade socioambiental e econômica na escola e em qualquer lugar que esteja tendo em vista comprovar nas ações de sustentabilidade executadas por toda comunidade escolar em estudo. Foi percebido que as contas de consumo de energia tiveram descontos que variam entre $67 \%$ de economia e impactando positivamente nos meios físico (água, ar e solo), biótico (flora e fauna) e antrópico (a população) de forma ambientalmente adequada. 
Os alunos replicaram as ações nas suas residências e com isso promoveram qualidade de vida às suas famílias. 0 modelo de combate ao desperdício de energia elétrica sinaliza que pode ser replicado nas demais escolas públicas e privadas do território brasileiro.

\section{Conflito de interesses}

Os autores declararam que não haver conflito de interesses.

\section{Referências}

Acserald, H. Sentidos da sustentabilidade urbana. In: Acserald, H. (Org.). A duração das cidades: sustentabilidade e risco nas políticas urbanas. 2. ed. Rio de Janeiro: Lamparina, 2009.

Alva, E. N. Metrópoles (in)sustentáveis. Rio de Janeiro: Relume-Dumará, 1997.

Alves, L. A. Cidades saudáveis e qualidade de vida em Uberlândia (MG): aportes metodológicos para um processo em construção. Uberlândia: Universidade Federal de Uberlândia, 2016. (Tese de doutorado).

Buss, P. M. Só há desenvolvimento sustentável com uma população saudável. Centro de Relações Internacionais em Saúde. Entrevistadora: Marina Lemle, Rio de Janeiro. 25 jun. 2012. Disponível em: <http://ecos-crisfiocruz.bvs.br/tiki-read_article.php?articleId=24>. Acesso em: 24 ago. 2020.

Brasil. Lei no 9.795, de 27 de abril de 1999. Dispõe sobre a educação ambiental, institui a Política Nacional de Educação Ambiental e dá outras providências. Disponível em: <http://www.planalto.gov.br/ccivil_03/leis/19795.htm>. Acesso em: 25 jan. 2020.

Carvalho, M. L. F. Políticas de gestão dos resíduos sólidos domiciliares na Cidade de Fortaleza-Ceará: avanços e desafios. João Pessoa: Universidade Federal da Paraíba, 2016. (Dissertação de mestrado).

Cervi, J. L.; Carvalho, P. G. M. A pegada ecológica: breve panorama do estado das artes do indicador de sustentabilidade no Brasil. Educação Ambiental em Ação, n. 38, p. 1-14, 2016.

Dias, G. F. Pegada ecológica e sustentabilidade humana. São Paulo: Gaia, 2002.

Diegues, A. C. Desenvolvimento sustentável ou sociedades sustentáveis: da crítica dos modelos aos novos paradigmas. In: Diegues, A. C. Ecologia humana e planejamento em águas costeiras. São Paulo: NUPAUB, 1996.

Foladori, G. Limites do desenvolvimento sustentável. Campinas: Ed. UNICAMP, 2001.

Leroy, J.-P.; Pacheco, T. Dilemas de uma educação em tempo de crise. In: Loureiro, C. F. B. (Org.). Pensamento complexo, dialética e educação ambiental. São Paulo: Cortez 2006.

Martins, C. Ceará é referência em produção de biogás. A Tarde, 2018. Disponível em: <http://atarde.uol.com.br/economia/noticias/1964852-ceara-e-referencia-em-producaode-biogas-com-maior-usina-do-brasil>. Acesso em: 28 dez. 2018.

Sauvé, L.; Berryman, T.; Brunelle, R. International proposals for environmental education: Analysing a ruling discourse. Atas da Conférence Internationale sur l'Éducation Relative à l'Environnement "Environmental Education in the Context of Education for the 21st Century: Prospects and Possibilities", Larisa, Grécia, 2000, p. 42-63, 2002.

Rev. Bras. Gest. Amb. Sustent., 2020, vol. 7, n. 17, p. 1241-1256. 
Schmieder, A. A. Natureza y princípios generales de la educacion ambiental: fines y objetivos. In: UNESCO - Organização das Nações Unidas para a Educação, a Ciência e a Cultura. Tendências de la Educacion Ambiental. Paris: UNESCO, 1977. p. 25-38.

Vianna, J. N. S. Energia e meio ambiente no Brasil. In: Bursztyn, M. (Org.). A difícil sustentabilidade: política energética e conflitos ambientais. Rio de Janeiro: Garamond, 2001.

Informação da Licença: Este é um artigo Open Access distribuído sob os termos da Licença Creative Commons Attribution, que permite uso irrestrito, distribuição e reprodução em qualquer meio, desde que a obra original seja devidamente citada. 